\title{
The Pragmatic Believer-Faith Development and Personal Experiences of a 'Higher Power' in Seasoned Members of Narcotics Anonymous
}

\author{
John-Kåre Vederhus ${ }^{1}$ and Magnhild Høie ${ }^{2}$
}

\begin{abstract}
Health policy organizations recommend that health professionals refer patients with a substance use disorder to addiction-related self-help groups. However, the most common groups, the 12-step groups (e.g., Narcotics Anonymous [NA]) have religious wording (e.g., God, Higher Power, prayer) in their program that may cause potential participants to be sceptical, especially in secular cultures. From seven interviews with seasoned members of NA in Norway, we explored how the Higher Power concept of NA's 12-step program is understood, how the respondents relate to their Higher Power in daily life, and whether they describe it as helpful in their recovery. A cross-case thematic analysis with systematic text condensation was used to analyze the data. Even the highly integrated NA members recounted an initial problem with the Higher Power concept. Eventually, the respondents realized that it was up to them to define the nature of their Higher Power. The respondents also defined the concept in secular or pseudo-religious ways. They were pragmatic believers; from early on they practised the recommended spiritual principles in NA (e.g., honesty and altruism), and dogmatism was considered unnecessary. The respondents presented relating to their Higher Power as vital for recovery, as they found motivation and strength to cope with the everyday process of staying clean and to continue in a recovery process. The present study sheds light on how secular and/or pragmatic, pseudo-religious worldviews can function similarly to specific religious views by helping people cope with demanding life experiences. The openness in NA toward diverse worldviews facilitates mutual support between members in a recovery process, despite differences in religious or spiritual persuasions. Health professionals should help potential participants overcome initial scepticism towards 12-step groups in order to gain access to the abstinence-based support obtainable in these fellowships.
\end{abstract}

1 Corresponding author: John-Kåre Vederhus, Addiction Unit, Sørlandet Hospital HF, P.O. Box 416, 4604 Kristiansand, Norway; john-kare.vederhus@sshf.no.

2 Magnhild Høie, University of Agder, Grimstad, Norway.

(C) KONINKLIJKE BRILL NV, LEIDEN, 2019 | DOI:10.1163/9789004382640_008

This is an open access article distributed under the terms of the prevailing CC-BY-NC license at the time of publication. 


\section{Keywords}

Alcoholics Anonymous - faith development - Narcotics Anonymous - Norway recovery - relational spirituality theory - substance use disorders

The concept of spirituality has received increasing attention in addiction research (Cook, 2004), with some authors emphasizing it as a key concept in the recovery process (Galanter, 2006; Laudet, Morgen, \& White, 20o6; Miller, 2003). In a review focused on addiction and spirituality, $60 \%$ of the included articles were related to the 12-step philosophy, indicating a permeation of this theme in the addiction field (Cook, 2004). The founders of the first 12-step fellowship, Alcoholics Anonymous (AA), came to understand alcoholism as an illness that only a spiritual experience could conquer; thus, their 12-step program focused on the need for a spiritual awakening and to employ spiritual principles (e.g., honesty, gratitude, and altruism) in order to counter the desire to use alcohol (Alcoholics Anonymous, 2014, p. 56).

AA's ideals and program were adapted from the principles and practices of an evangelical Christian organization, the Oxford Group, to the specific problem of the inability to control drinking (Mäkelä et al., 1996). The heritage from the Oxford Group is still evident by the fact that six of the 12 steps contain words normally perceived to be purely religious concepts, including 'God' and 'Higher Power', which some name the 'Higher Power mediated steps' (Harris et al., 2003). These two concepts, God and Higher Power, will be used interchangeably in accordance with their usage in the 12-step program. From early on, AA renounced that members ought to have a specific definition of God, and it was left up to the individual to define the nature of his/her Higher Power, be it secular (e.g., the fellowship, the group), religious, or some other form of worldview, as noted in the third step: "God, as we understood Him" (Zemore, 2008). This understanding of the 12 steps is quite well-known in the 12-step groups' country of origin, the United States, but research in some European countries indicates that it is less known in Europe among both potential attendees and professionals (Harris et al., 2003; Vederhus, Laudet, Kristensen, \& Clausen, 2010).

Health policy organizations, such as the World Health Organization, recommend that health service organizations rely more on mutual help in the global strategy to counter addiction (World Health Organization, 2010). Similarly, the treatment guidelines for substance use disorders issued by the American Psychiatric Association recommend referrals to a 12-step group at all stages 
of the treatment process (Kleber et al., 2007). However, European professionals seem to have a reserved, or even reluctant, attitude towards these groups (Vederhus, Kristensen, Laudet, \& Clausen, 2009). One of the key issues for European professionals seems to be a lack of distinction between religion and spirituality, interpreting the steps that refer to a Higher Power as having only religious associations (Day, Gaston, Furlong, Murali, \& Copello, 2005). A cross-cultural study including addiction professionals from the present cultural context found that $70 \%$ of Norwegian clinicians consider the religious connotations in AA's 12 steps to be an obstacle for many patients, compared to only $29 \%$ of U.S. clinicians (Vederhus et al., 2010). Furthermore, health professionals in Norway are quite uneasy with linking the concept of spirituality to their professional practice; it is considered to belong to the domain of religion (Furman, Zahl, Benson, \& Canda, 2007; Vederhus, 2017). Thus, to enhance cooperation between formal treatment services and these peer-based recovery resources, an effort should be made to examine how the religious wording in the 12-step program is used and understood by members, potentially bridging the professional and mutual-help gap (Olson, Jason, \& Hutcheson, 2005).

Tentative analyses have examined 12-step program members' understanding of their Higher Power in the framework of the psychology of religion and spirituality, but the attempts have been few (Fowler, 1993; Harber, 2005). In light of the known obstacles towards enhanced use of these groups and recommendations to use mutual-aid alternatives more, further studies are warranted to better understand the Higher Power principle in 12-step programs and the mechanisms at work in these voluntary recovery resources.

\section{$1.1 \quad$ Objectives}

In the context of Norway, we set out to explore how seasoned members understand the Higher Power concept of their program. We also examined how they relate to this concept in their daily life and whether they describe it as helpful in their recovery.

\section{Methods and Theoretical Framework}

\subsection{Theoretical Frame of Reference}

The term God concept ${ }^{3}$ used in the field of the psychology of religion and spirituality can be defined as a person's set of beliefs about a specific divine

3 Davis et al. (2012) suggested using a lowercase $g$ to underscore the commonality of the concept. Although we agree with this view, we use uppercase when speaking about God and 'Higher Power' in this article in accordance with custom usage in the 12-step programs. 
attachment figure, or how humans think about that divine attachment figure (Davis, Moriarty, \& Mauch, 2012). Because 'God concept' in this framework is a psychological construct, it can be used as a basis for in-depth understanding of humans without having to take a stand on the metaphysical existence of God (Hoffman, 2012). However, God images refers to the individual's attachment profile (Bowlby, 1973) influencing most interpersonal relationships, including relationship with God (Davis et al., 2012; Hoffman, 2012). Thus, 'God images' reflect how a person experiences and relates to a divine attachment figure at an emotional level (Davis et al., 2012). The theoretical division is useful, as one could have a clear conceptualization of a benevolent God, but it does not necessarily follow that this knowledge means much to one's actual life here and now; a low correspondence may exist between one's conceptual, head knowledge schemas and emotions (Olson et al., 2016). As Fowler (1986, p. 23) stated, there is a difference between objectively knowing something with the "logic of rational certainty" and knowing something with the "logic of conviction", with "a spread of meaning, a canopy of significance, composed to backdrop or fund more immediate, everyday action". Some characteristic styles have been described in how a person relates to a Higher Power and how involved a person is with his/her Higher Power in everyday life (Pargament, 1997). Two styles appear to contrast; in the self-directing approach, people rely on themselves rather than on God and perceive the self as being the centre of control, whereas in the deferring approach, the person renounces control and the responsibility for acting is passively deferred to God. In a third approach, the collaborative approach, the individual and God are both active partners.

Due to the special nature of the Higher Power concept in 12-step philosophy, it is necessary to have a broader, more generic view than 'divine attachment figures'. Thus, we find the concepts 'centers of value' and 'ultimate frame of reference' in Fowler's definition of faith relevant:

Faith, here, refers to the personal actions and responses involved in awakening to meanings and values, and in committing the self to centers of value, images and reality of power, and core stories that link persons to others who share them, and to an ultimate frame of reference which give them coherence.

FOWLER, 1993, p. 114

In this sense, faith in something beyond the self is generic and universal in humans, and has to do with the making, maintenance, and transformation of human meaning. This can include religious faith but is not reducible to it, an understanding that is a suitable point of departure for the present examination. 


\subsection{Setting and Participants}

In the present qualitative study, we explored the views and experiences of seven long-term attendees ('old-timers') of Narcotics Anonymous (NA), a 12-step recovery fellowship that adapted the AA program to other substances of abuse in the 1950s (Table 1, Laudet, 2008; Narcotics Anonymous, 2016). NA's understanding of identifying as addicts is all-inclusive with respect to moodchanging substances (Narcotics Anonymous., 2008). NA gained a foothold in Norway approximately 25 years ago and has been steadily growing. Currently, there are 134 weekly group meetings nationwide ( $>3$ per 100,000 inhabitants), almost as many as AA. Respondents in the present study came from two large cities in Norway. NA attendees known by the first author informed other potential participants in NA about the study and asked if they were willing to participate; those who were willing were contacted by the researchers. Participants included four men and three women aged $37-5^{8}$ years (average 50 years). Regular attendance of NA ranged from 4 to 23 years (average 11 years), with 5 of the 7 having attended $>500$ meetings in their lifetime. The participants were also regular attendees at present and had each been to approximately one meeting per week the last 6 months. Before participating in $\mathrm{NA}$, the respondents had severe life problems as a consequence of their drug use, such as family disruption, social problems, and reduced physical and mental well-being. Some of the respondents had been involved in serious criminal activities and spent several years in prison before the age of 30 . All except one had been treated for their addiction on one or more occasions in the specialized substance use disorder (SUD) treatment services. For all respondents, this treatment occurred more than 4 years ago.

\subsection{Interviews}

Data were obtained from interviews with participants that were conducted by both authors in 2014/2015. Participants were interviewed once for approximately 90 minutes. The participants chose whether the interview would occur on 'neutral' ground at the local university or at the local addiction treatment centre. A thematic interview guide was developed. First, the participants were asked to briefly narrate their life before they came to NA, and how and why they became involved in NA, with a particular focus on their first experiences in the fellowship. Respondents were also given the opportunity to elaborate on their understanding of the NA program and how they understood the 'Higher Power' concept. A central theme was how they related to their Higher Power in everyday life. The interviews were recorded digitally and later transcribed verbatim by the authors. 
1 We admitted that we were powerless over our addiction, that our lives had become unmanageable.

2 We came to believe that a Power greater than ourselves could restore us to sanity.

3 We made a decision to turn our will and our lives over to the care of God as we understood Him.

$4 \quad$ We made a searching and fearless moral inventory of ourselves.

5 We admitted to God, to ourselves, and to another human being the exact nature of our wrongs.

6 We were entirely ready to have God remove all these defects of character.

7 We humbly asked Him to remove our shortcomings.

8 We made a list of all persons we had harmed, and became willing to make amends to them all.

9 We made direct amends to such people wherever possible, except when to do so would injure them or others.

10 We continued to take personal inventory and when we were wrong promptly admitted it.

11 We sought through prayer and meditation to improve our conscious contact with God as we understood Him, praying only for knowledge of His will for us and the power to carry that out.

12 Having had a spiritual awakening as a result of these steps, we tried to carry this message to addicts, and to practice these principles in all our affairs.

\section{$2.4 \quad$ Ethics}

The Regional Ethics Committee of the South-East Health Region, Norway, waived the need for ethical approval of the study (REC no. 2013/602). However, the study was approved by the NSD Data Protection Official for Research (NSD no. 2013/34650) and conducted in accordance with the Norwegian Personal Data Act. All participants were given written and oral information about the study and signed an informed consent form. No incentives were offered to participants.

\subsubsection{Analysis}

The interviews were analysed by systematic text condensation (STC), a method for cross-case thematic analysis of qualitative data adapted after the Giorgi method (Malterud, 2012). The purpose of STC is to examine how 
the respondents experience their world of life in a certain field by looking for essential characteristics of the phenomenon under study. The method involved reading all of the material to obtain an overall impression and recognize preliminary themes; further elaboration of meaning units and coding them based on preliminary themes representing different aspects of participants' experiences with their Higher Power; establishing subgroups within code groups to exemplify aspects of each, condensing the contents and finding illustrative quotations; and summarizing the contents of each code group to generalize descriptions and concepts concerning participants' relationships with their Higher Power. Both authors read the material and participated in elaborating themes and interpreting the findings.

\subsection{Preconception}

One of the authors had more than 20 years of clinical experience with SUD treatment and was familiar with the 12 steps and 12 -step groups. He previously advocated for more cooperation between the professional treatment system and 12-step-based mutual help groups (Vederhus et al., 2009; Vederhus, Timko, Kristensen, Hjemdahl, \& Clausen, 2014). Thus, his preconception about such groups was fundamentally positive. The other author had less experience with the theme but had conducted research on other support groups and had a positive attitude towards such groups in general (Høie \& Sjøberg, 2007). Such familiarity with the field under study is considered a resource, as it can give a head start to knowledge on the topic and positively affect the information that respondents are willing to share. However, it also poses some problems, as the researcher may not be sufficiently aware of his or her own assumptions (Berger, 2015). In the Methodological considerations section below, we reflect on how our positive preconception may have influenced our assumptions and the interpretative process.

\section{3} Findings

Findings have been categorized according to the respondents' conceptual understanding of their Higher Power and how this was experienced on a relational and emotional level in their current daily life. Pseudonyms have been assigned to quoted text. 


\subsubsection{Initial Problems}

Four of the respondents had initial problems related to the Higher Power concept. When Elsa heard the word "God" at her first meeting, she was certain that this was some way of tricking her into a religious movement, although it was explicitly said that the word should not necessarily be understood in religious terms. Mats described the "God thing" as leading to his "claws coming out". Although he was attracted to the NA fellowship, he did not feel ready to become a Christian. Peter remembered that, when he first saw the 12 steps, he found some steps to be sensible, but concluded that "this is not for me" when he saw the "God" steps. Freddy was at once attracted to the fellowship and the atmosphere, but also had fears, as he was sceptical of religion. Thus, these respondents inferred from the 'God' word that NA was some kind of a Christian fellowship and were sceptical.

The respondents indicated at least three factors that were important to resolving this initial scepticism: they stayed because they sensed that NA offered hope to become free of drugs, they felt a loving and positive atmosphere at the meetings and experienced this as an attractive feature, and they received continued reassurance from mentors (i.e., 'sponsors') and other participants that you can choose your own definition of 'God'. Nonetheless, a few struggled with this problem for a long time.

It was nearly three years before I found my own faith. I finally felt free to stop searching and looking for answers in the others; I thought they could tell me-instead of searching in myself-what I believed in. It took a mighty long time.

ELSA

\subsubsection{Each Respondent Found their Own Higher Power}

The respondents' current perception of God/Higher Power was quite diverse. All respondents explicitly stated that members were granted the right to define the concept in their own way. This was perceived as a valuable feature of NA's God concept; the freedom to choose your own view. Two respondents had a typical Christian view; one had been a member of the Pentecostal church, the other had a Christian upbringing and said, "That is good enough for me, although I'm not a particularly active Christian." The other five respondents had different views, ranging from linking the Higher Power concept to secular concepts (e.g., support from the group and the resources available in the 12-step program) to other less well-defined existential concepts, including an 
open mind (i.e., "there is something there, but I haven't a clue what it is") and syncretic views (i.e., that humans essentially relate to the same transcendent source of faith although we have different thoughts of what that reality is). Despite these open or non-theistic notions connected to the Higher Power concept, the word "God" was still used as alternative to "Higher Power" when respondents talked about the concept.

I relate to a Higher Power ... a power stronger than me. I find it in the fellowship. I haven't spent energy to go deeply into it, who God is, whether it is a man or a woman, black or white. It would be like trying to explain the light.

ANN

\subsubsection{Commonalities in the Understanding of a Higher Power}

The most common denominator was that the Higher Power simply had to be something or someone beyond the self and perceived as something stronger than one's addiction. Peter named his Higher Power the positive X-factor in his life. He contrasted it with the negative X-factor; everything related to the drug and drug use. As little as he could explain the nature of the negative X-factor (i.e., how it was possible for him to ruin his life because of his obsessional drug use), he also found it difficult to explain the nature of his positive X-factor. Thus, he indicated that NA's Higher Power concept escaped classification to some degree. It was also clear in the respondents' elaboration of the theme that the Higher Power concept was a much more experience-based concept than doctrine-based. The Higher Power was not spoken of as some kind of an airy notion; it was spoken of as an experienced reality. For example, respondents referred to happenings in the past, such as surviving a car accident when driving under the influence of drugs and survival against all odds: "If God did not exist, I would not be here." The most prominent evidence, however, was the respondents commitment to be clean (i.e., not using drugs each day), pointing to the Higher Power at work in everyday life.

The Higher Power concept was very much linked to the fellowship itself, regardless of concept diversity. The fellowship was mentioned as a power having the ability to counter the addiction if one engaged in it and used it. This feature referred to the collective strength of the fellowship; being together with others who try to recover adds much compared to trying to recover on your own. Even principles, the structures built into the fellowship, were referred to as a possible Higher Power, the most central of which were the 12 steps and spiritual principles such as being "open, honest, and willing". Peter elaborated on how he experienced the Higher Power through the group, showing how intertwined the two concepts are: 
But that's me ... I don't really think too much about it, it is not what I first think about when I think about a Higher Power [i.e., how to define the concept]. A Higher Power for me is.... to go to a meeting ... and I sit there and sense the atmosphere around the table, and people come in there having a very hard time, and afterwards they leave very uplifted. PETER

Nonetheless, the Higher Power was not constrained to only being the collective power of the fellowship. One could say that the fellowship was thought of as a practical Higher Power principle and/or could point to something/someone beyond the fellowship itself.

\subsection{Relating to a Higher Power in Daily Life and in Recovery \\ 3.2.1 "I need help from someone outside me" — the Necessary Turning Point.}

The severity of the respondents' illness before they came to NA was summarized briefly with 'cold' facts in the section describing the participants. There were also strong emotional aspects connected to this, including gradual insight into the massive consequences of the substance use on oneself and important others, guilt and shame, feelings of alienation from others, realization of total failure in life, and utter despair. These insights into the seriousness of the condition seemed to be necessary preconditions for their turning away from drugs. However, as the respondents conveyed a realization of not being able to change by their willpower alone (being 'powerless'), the movement was not primarily a turning away from something (drug use), but a turning to something; they became willing to ask for help from resources outside themselves.

The turning point was not only described in terms of 'powerlessness', it was also referred to as an unexpected discovery of suddenly gaining hope. For example, Elsa was determined to end her own life, but Christmas was coming up and she felt it would be too horrible for her children if she ended her life right before Christmas. Therefore, she welcomed the opportunity to stay at a detox centre, waiting for the holidays to pass. During that stay, she heard for the first time another woman (an employee) tell about her own substance abuse, how she had been helped by the NA fellowship, and as a result had been clean for many years. Astonished, Elsa felt a glimpse of hope for the first time. Although her suicidal intention did not disappear, it decreased gradually during subsequent months; she accepted a referral to a treatment facility and began attending NA in parallel. 


\subsubsection{From Distrust to Trust}

The initial problem with the God concept was not the sole obstacle for participants. On a deeper level, the respondents found it difficult to even trust or relate to someone beyond the self, whether it was other people or some god. "It's about belief in something ... to trust in something ... I've never trusted anything before in my life." (Elsa). This lack of trust was also accompanied by a strong feeling of alienation from others. The basic mistrust seems to have been accentuated by participation in the fellowship (i.e., experiences of friendliness in the fellowship made participants more aware of it). Some participants used offensive strategies to resolve or ameliorate this problem, such as daring to speak at meetings and share emotions quite early on. Peter admitted that he probably said all the wrong things in his effort to come clean, but in the long run he found that this strategy helped him become well integrated into the fellowship. Others employed more passive strategies and spent a long time in the fellowship to develop more robust relationships with others and their peers. Rebuilding trust in external forces included trust in a Higher Power. Mats described previously having had the same thoughts about God as he had toward the police; someone watching his moves and punishing him if he does something wrong. His experience with the 12-step program led him to gradually change his mindset and to think of his Higher Power as a benevolent guide.

\subsubsection{A Miracle Emerging}

Based on the respondents' descriptions of their severe situations, it is not difficult to understand that they referred to the possibility of living a meaningful life again as a miracle. An overall view was that NA and a Higher Power had been the main moderators of this miracle. In addition to simply being alive despite the despair and seriousness of the condition, this miracle included the perception of being freed from the compulsive urges to use drugs, to perceive a meaning to life despite feelings of loss and defeat, and being freed from shame and fear.

It dawned on me that the only thing I had not tried was to pray, simply pray to God for help. So I did just that; I started to pray and asked for some power, and I got a completely strange feeling. I went from a world completely dominated by non-belief ... I never even considered it, it was a non-issue. Suddenly, it was something I opened up to. And ... that's what I call the miracle of my life. I cannot explain how it happened, but it did. And I kept it with me when I moved on. 


\subsubsection{Grow or Perish}

As stated above, accepting powerlessness when it came to using drugs was a necessary first step to stop their use and start recovery. Powerlessness also included the notion that self-will at any point in time could be deceived by the cues and urges to use again. Thus, the abstinence-based support obtainable in the fellowship was much appreciated. Nonetheless, respondents underscored that, if you stay the same person, if you do not change, you will start using again sooner or later. A transformation or personal growth process was necessary to stay clean in the long run and to create a life worth living. Merely attending meetings may not be enough; you were recommended to 'work the steps' (i.e., put the principles into action), such as by trying to help others by sharing your story and allowing others to help you (e.g., your sponsor). Tools in this process were the fellowship and the people there and to engage in a deeper understanding of the principles in the program (the 12 steps) and in communication with the Higher Power.

The first years I merely attended meetings and felt such a joy that I stayed clean and sober. I did not occupy myself with those concepts at the time [e.g., Higher Power, spiritual awakening]. I was only happy that I didn't want to use drugs and that I didn't have to sit by myself and bite my nails. But after three years I felt I'd come to a dead end, I had no progress anymore, I felt stranded. My fears and anxiety did not disappear. I was the same person ... or almost the same as when I came to the first meeting. That's when I decided to take the program seriously; it was a decisive turning point for me. I had a choice; I could have started to use drugs again, but I chose to use the program. I got a sponsor and I started to talk about how I really felt about being me. I started to be honest and to work on the steps [to write up her personal account about the steps and talk with her sponsor about it]. It's not easy to grasp all of it, it takes some time to really come to terms with it ... what's the meaning of each step, it's not done overnight.

ANN

\subsubsection{Daily Communication with the Higher Power}

As an extended resource beyond the collective strength of the fellowship, all respondents described some form of communication with their Higher Power to attain power to cope with life. Prayer was mentioned in some of the respondents' histories before they came to NA. In his search for help, Freddy had read about a drug addict who became a Christian. After reading the book, he found himself praying to God. Shortly thereafter he was granted a stay at a 
faith-based residential treatment centre and he interpreted it as a response to his prayer. Later at the centre, he became opposed to a typical Christian view of God and was not impressed with the treatment there, but he was introduced to NA and became very much attracted to the fellowship. He later interpreted his first prayer as a "spiritual awakening", indicating that it was a strongly emotional event and a turning point in his life.

All respondents practiced some form of prayer or meditation in their everyday life. ${ }^{4}$ Meditation ranged from just experiencing and 'talking' with the Higher Power in nature, to using NA's daily reflection book (Just for today), trying out meditation as a part of an ordinary NA meeting, and practicing prayer and/or meditation on their own. Respondents described prayer and/or meditation as a daily routine and denied that it felt like a compulsory activity; it was seen as a wanted and needed routine. The effects of prayer and meditation were, for example, to become "grounded", to be "present" in one's own life, keeping in mind the most important things in life (to stay clean was described as the no. 1 priority), remembering to be thankful, and starting off the day in a thoughtful way. It was also used as a way of expressing and becoming aware of feelings and emotions or to vent negative emotions. The important matter was to pray (or meditate); the focus was not on the form or to whom you prayed.

When I pray, I give words to thoughts and feelings, things I don't want to talk about in the meetings, it's between me and God. How I do it is not important, what's important is that it makes me feel better. By putting my worries into words, I can say: “OK, now I've put it away, I cannot do more with this now."

ELSA

Several respondents described "sacred moments" in association with the dialogue with their Higher Power. This was connected to the important turning points, but subtler emotional experiences in daily life were also referred to as "spiritual awakenings".

The first time we went hiking, we were out on a lighthouse. I was clean and sat alone out on the rocks by the sea, with a cup of coffee ... and I felt the air and the breeze ... it was a spiritual experience for me at the time, to feel such peace and satisfaction. I'd never felt that way before. Never! It was a strongly motivating experience. It can also be such little things: to

4 Prayer and meditation are explicitly mentioned in Step 11, see Table 1 (Narcotics Anonymous., 2008). 
appreciate things, to experience real happiness. To be a drug addict and feel real joy, that's a spiritual experience!

ANN

\subsubsection{What's Up to God and What's Up to Me?}

A general impression of the respondents was that they were self-confident and engaged in telling about their fellowship; they did not seem to be 'brainwashed' by some ideology or to play a passive role in their own recovery. They underscored that it was necessary to take an active role in the recovery process if they wanted to recover, and it was presented as a contrast to the tendency of the addict to avoid taking responsibility. Freddy was very clear on his own role versus that of his Higher Power: "I don't believe in a Santa Claus-God who gives me all I want-I believe you have to do what you can yourself." However, it was also clear that success was not dependent on just 'doing it on your own', it was a question of the collaborative effort between yourself, your Higher Power, and the resources available in the group. Nevertheless, in some areas (e.g., when thinking back on all the wrong they had caused to others and when they were overwhelmed by guilt and shame), they underscored that it was important to 'hand matters over to God' to keep their head above water. The serenity prayer was mentioned as one way of doing this:

God, grant me the serenity to accept the things I cannot change, Courage to change the things I can,

And wisdom to know the difference.

\section{4 \\ Discussion}

We found that even highly integrated NA members had initial problems approaching the fellowship. As reported by others, it was the Higher Power concept and the use of religious concepts in the 12-step program that caused the most scepticism (Harris et al., 2003). We interviewed respondents who had 'kept coming back' and eventually became NA engagers, but it is likely that these kinds of problems would make other attendees drop out. Few data on NA disengagement exist, but an analysis of AA member surveys found a $56 \%$ drop-out rate after six months (Chappel, 1993). On the other hand, one could say that the respondents' stories in the present study indicate that it is possible to overcome initial scepticism. This conclusion was based both on the local groups' success in accommodating and addressing such scepticism, and on the individual's perception of needs, as the respondents were desperately aware 
that they were unable to refrain from drug use on their own. Thus, they seemed to have taken the necessary stance as recommended by a Norwegian addiction researcher when he spoke about social and cultural assimilation into the NA environment: "When in Rome, do as the Romans do" (i.e., you may not understand everything, but stay there and use the time until you get acquainted with the fellowship and its principles) (Fekjær, 2004, p. 246).

As expected, diversity was found in the definition of a Higher Power, which seemed to reflect society at large. Homogenous beliefs regarding religious faith in Norway have deteriorated in the past half century; belief in a personal God declined from $85 \%$ in 1965 to $50 \%$ in 2005 (Botvar, 2009). In an international cross-cultural study of religion, only $15 \%$ of Norwegians agreed with the statement, "I know God really exists and I have no doubts about it", whereas as many as $61 \%$ of U.S. citizens agreed with the same statement (Bechert \& Quandt, 2013). The difference is stunning in light of the fact that the U.S. practices secularism, state neutrality with respect to different religions and religious practice, whereas Evangelical Lutheran has been the official state religion in Norway for centuries (Zahl, 2003). Yet, in 2009, 81\% of Norwegians were members of the state church (Schmidt, 2010). After a long process, state and church were finally separated by law in 2012 and the Norwegian state took the last step towards secularism (Hovdelien, 2014). In a way, one could say that NA practices secularism in the true definition of the word, an acceptance of pluralism and the realization that people think differently when it comes to religious questions. For the individual member, this entails not merely adopting others' ideas; to really come to terms with the Higher Power concept, you have to engage in a personal process, such as deepening your understanding through literature, meditation, and working the steps.

Although the respondents' views also included a secular version of the Higher Power concept, their worldview can hardly be described as 'secularized' in terms of being separated from religious or spiritual influences, or as being unspiritual. NA claims to be a spiritual program, not a religious program (Narcotics Anonymous., 2008), and the emphasis respondents placed on spirituality and existential issues was evident in their stories and everyday life. We would like to call the respondents 'pragmatic believers'; as long as something works, stick with it. In more concrete terms, you could say "as long as the principles of NA work, they also evidence a Higher Power, regardless of whether you have a clear perception of the concept or not." Some respondents also suggested new members unfamiliar with the Higher Power concept consider the 12-step program and other 12-step resources (e.g., the 12-step literature) as their Higher Power. One might think of such principles as the resources available in the fellowship (e.g., consider the 12 steps as suggested strategies for change 
to guide the individual in their recovery). Such principles are akin to 'rules of life' that must be 'worked with' (i.e., practiced in daily life and may not be communicated with as you would a theistic Higher Power). Nonetheless, as the principles in the NA philosophy are connected to a theistic frame of reference (God/Higher Power) and also include religious elements (prayer), they may pave the way for becoming more open-minded toward worldviews that draw on some form of theistic religious tradition. One may call it agnostic theism (i.e., having an open mind towards the possibility of a transcendent God) (Smith, 1979). Because the members are faced with the 12-step program's religious overtones and spiritual sides, they are probably more likely to ponder these matters than the general population (Ólafsdóttir, 2000). However, we noticed that none of the respondents seemed to have found religion through NA. Notably, some respondents had experiences with a Higher Power before they came to NA, experiences that they later interpreted as 'spiritual awakenings'. Thus, it seemed like an inductive process; the experiences were not induced by the NA philosophy but were later interpreted to correspond with the 12-step program. Such perceived correspondence with one's own life may have made the respondents more likely to embrace the program in full.

Dogmatic knowledge about transcendent powers seemed to be unnecessary for the respondents, a tendency that is also seen in society at large. A recent regional study of religious change found less focus on dogma and more focus on emotions and positive experiences compared to earlier studies (Repstad, 2009). The important issue for the present respondents was to begin practicing the recommended principles in NA. These were considered to be common and valid across different religions and independent of theistic or non-theistic worldviews; they were considered "spiritual principles" and seen as part of a global spiritual heritage from which the individual could derive power. An example was the altruistic part of the NA program; helping others was presented as being central to the respondents' own recovery. The modern search for spirituality has had a tendency to be preoccupied with exercises that are supposed to have an effect on personal maturation and well-being. Unmitigated, this can be regarded as a self-centred and even narcissistic journey (Engedal, 2006). Due to NA's focus on helping others, the present respondents' spirituality was practical in the sense that its focus was not primarily on self-fulfilment. Thus, the program turned the respondent away from the potential narcissistic perversion "what's in it for me" to "what can I do for others". Personal growth would then be a secondary reward and, as such, the NA program seemed to protect the respondents from the narcissistic tendency in the modern search for spirituality (Hart \& Huggett, 2005). 
Despite the rather unclear and undogmatic understanding of the Higher Power concept, the functional aspect of the concept was very much apparent in each respondent's life. In contrast to the distance between God and humans you would expect in an agnostic framework in which one regards the existence of a God as inherently unknowable (Smith, 1979), the Higher Power was imminent and present in each respondent's life. To believe in a Higher Power was an issue in the important turning points in the respondents' life, and the respondents had a regular relationship with their Higher Power that gave them strength to cope in their everyday life. It was evident that their God image, the relational schemas that underlie the person's experiences in that relationship, had undergone a substantial change for the better. They had gone from distrust to trust and developed a strong positive attachment to their Higher Power, though most of them had not settled down in traditional theistic religious frames of reference. The respondents were certainly pragmatic believers, in that they experienced emotional support from their Higher Power in everyday life, despite having less clear head knowledge (or theology) of that reality. Such perceived support was founded on the empirical evidence in their life rather than dogmatic schemas. These findings are in stark contrast to those observed in university students from two faith-based universities who underwent a group-based intervention focused on promoting positive changes in God images and attachment to God (Olson et al., 2016). The somewhat disappointed researchers reported mainly null results, although the participants were described as individuals who sought spiritual growth experiences that would help them nurture positive change in their spiritual life and their perceived relationship with God. The studies are quite diverse and comparisons are somewhat speculative, but the perceived lack of God attachment in the university students compared to the strong attachment to a Higher Power present in the NA sample may be due to differences in needs. The NA sample was quite clear that they "could not do without" their Higher Power, whereas university students may generally have a stronger perception of being selfsufficient even though they have spiritual ideals.

The respondents in the present study did not consider themselves selfsufficient and did not have a self-directing relationship with a Higher Power (i.e., they did not rely on themselves rather than on God) (Pargament, 1997). Their relationship with a Higher Power was not of a 'deferring' type, in which the responsibility for acting was passively deferred to God, as they were well aware that they had to take responsibility for following the recommended change strategies (the program) if they wanted to remain in the recovery process. Thus, the 'powerlessness' principle in NA did not induce passivity and 
was not used as an excuse or as a way of ducking responsibility as some critics have stated (Leighton \& Barton, 2005). Rather, it seemed to be a precondition for action (Ólafsdóttir, 2000; Vederhus, Timko, Kristensen, \& Clausen, 2011). The paradox seemed to be as follows: "You alone can do it, but you cannot do it alone" (i.e., it is a collaborative effort between the individual, the fellowship and the Higher Power). However, in situations in which there was nothing much you could do to change the situation or the matter at hand, including when it was difficult to handle negative emotional states, the respondents simply had to "hand matters over to God". This approach seemed to function as a way of changing oneself and accepting the world or life as it is and adjusting to it. This strategy seems to be in line with Lazarus \& Folkman's emotion-focused coping strategy, which is considered to be especially valuable in low-control situations with a limited chance of achieving successful outcomes by performing activities directed at controlling or changing the external world (Lazarus \& Folkman, 1984). The NA respondents involved and relied on their Higher Power in such emotion-focused coping processes, as seen in their use of the 'Serenity Prayer'.

\subsection{Methodological Considerations and Implications}

How does this study relate to the question of health professionals' referral of patients to 12-step groups? Our findings indicate that it is possible to overcome scepticism when participants trust that they can utilize an individualized understanding of religious terminology. Furthermore, scepticism can be reduced by a de-stigmatization of religious language and themes over just spiritual language. If health professionals prepare patients for these potentially controversial aspects of the 12 steps, they could facilitate involvement.

Due to our positive preconception of 12-step groups, we acknowledge that we have been inclined to assume that scepticism can, in fact, be overcome. As we used a purposive sampling procedure we also approached members who had accepted the fellowship's recommended ways of handling these questions. It is not likely that all participants, possibly not even a majority of potential participants, will be able or willing to change their perceptions of terminology to fit with the 12 steps. Therefore, we would like to stress that recommendations to patients should not be posed as an obligation to participate, which would violate the integrity of the individual. Instead, it should be posed in a frame of suggestions to 'try out' the fellowship (Bean-Bayog, 1993). Furthermore, viable secular alternatives should be recommended as equal alternatives, i.e., mutual-help groups without religious connotations in their program. Although few such alternatives are currently available in Norway, the number is fortunately growing. Approaches like these would likely reduce both professional and patient unease and scepticism. Future studies should 
also include individuals who have dropped out of 12-step groups in order to deepen our understanding of recovery, with or without the help of spiritual programs.

\section{5}

\section{Conclusions}

NA's 'non-denominational' framework and openness toward diverse worldviews facilitate members giving each other important support in a recovery process, despite religious and spiritual differences. Health professionals should recommend their patients try this fellowship, as well as secular alternatives, in order to enhance their chance of staying clean and continuing in long-term recovery.

\section{Acknowledgements}

We thank research fellow Bente Birkeland for valuable input on the manuscript.

\section{References}

Alcoholics Anonymous. (2014). Alcoholics Anonymous-The story of how more than one hundred men have recovered from alcoholism (Reprint of the original 1939 version). New York City: Alcoholics Anonymous World Services, Inc.

Bean-Bayog, M. (1993). AA Processes and Change: How Does It Work? In B. McCrady \& W. R. Miller (Eds.), Research on Alcoholics Anonymous (pp. 99-112). New Brunswick, USA: Rutgers Center of Alcohol Studies.

Bechert, I., \& Quandt, M. (2013). Issp Data Report: Religious Attitudes and Religious Change. Retrieved from Köln.

Berger, R. (2015). Now I see it, now I don't: Researcher's position and reflexivity in qualitative research. Qualitative Research, 15(2), 219-234. doi:10.1177/1468794112468475.

Botvar, P. K. (2009). Alternative Religion-A New Political Cleavage? An Analysis of Norwegian Survey Data on New Forms of Spirituality. Politics and Religion, 2(3), 378-394.

Bowlby, J. (1973). Attachment and loss: Vol. II: Separation. New York, NY: Basic Books.

Chappel, J. N. (1993). Long-term recovery from alcoholism. Psychiatric Clinics of North America, $16(1), 177^{-187}$.

Cook, C. C. (2004). Addiction and spirituality. Addiction, 99(5), 539-551. doi:10.1111/j. 1360-0443.2004.00715.x. 
Davis, E. B., Moriarty, G. L., \& Mauch, J. C. (2012). God Images and God Concepts: Definitions, Development, and Dynamics. Psychology of Religion and Spirituality, $5(1), 51-60$.

Day, E., Gaston, R. L., Furlong, E., Murali, V., \& Copello, A. (2005). United Kingdom substance misuse treatment workers' attitudes toward 12-step self-help groups.Journal of Substance Abuse Treatment, 29(4), 321-327. doi:10.1016/j.jsat.2005.08.009.

Engedal, L. G. (2006). Homo Viator: the search for identity and authentic spirituality in a post-modern context. In K. Terri (Ed.), Religion, Spirituality and Identity (pp. 45-64). Bern: Peter Lang Publishing.

Fekjær, H. O. (2004). Rus: bruk, motiver, skader, behandling, forebygging, historie (2. ed.). Oslo: Gyldendal norsk forlag AS.

Fowler, J. W. (1986). Faith and the Structuring of Meaning. In C. Dykstra \& S. Parks (Eds.), Faith Development and Fowler (pp. 15-42). Birmingham, Alabama: Religious Education Press.

Fowler, J. W. (1993). Alcoholics Anonymous and faith development. Research on Alcoholics Anonymous: Opportunities and alternatives (pp. 113-135). Piscataway, NJ: Rutgers Center of Alcohol Studies; US.

Furman, L. D., Zahl, M.-A., Benson, P. W., \& Canda, E. R. (2007). An international analysis of the role of religion and spirituality in social work practice. Families in Society, $88(2), 241-254$.

Galanter, M. (2006). Spirituality and addiction: a research and clinical perspective. American Journal on Addictions, 15(4), 286-292. doi:10.1080/10550490600754325.

Harber, G. S. (2005). God Image, Self-Image and lenght of abstinence among active members of Alcoholics Anonymous. Capella University, Minneapolis, MN.

Harris, J., Best, D., Gossop, M., Marshall, J., Man, L. H., Manning, V., \& Strang, J. (2003). Prior Alcoholics Anonymous (AA) affiliation and the acceptability of the Twelve Steps to patients entering UK statutory addiction treatment. Journal of Studies on Alcohol, 64(2), 257-261.

Hart, K. E., \& Huggett, C. (2005). Narcissism: A Barrier to Personal Acceptance of the Spiritual Aspect of Alcoholics Anonymous. Alcoholism Treatment Quarterly, 23(4), 85-100. doi:10.1300/Jo20v23no4_o6.

Hoffman, L. (2012). Religious Experience, Development, and Diversity. Pastoral Psychology, 61, 1025-1035.

Hovdelien, O. (2014). “... in favour of secularism, correctly understood.". Australian eJournal of Theology, 21(3), 234-247.

Høie, M. M., \& Sjøberg, B.-M. D. (2007). Damned, loved child: Drug abuse in light of close relatives experiences. [Forbannede, elskede barn-narkotikamisbruk sett i lys av pårørendes erfaringer]. Oslo: Cappelen Akademisk. 
Kleber, H. D., Weiss, R. D., Anton, R. F., Jr., George, T. P., Greenfield, S. F., Kosten, T. R.,... Steering Committee on Practice, G. (2007). Treatment of patients with substance use disorders, second edition. American Psychiatric Association. American Journal of Psychiatry, $164(4$ Suppl), 5-123.

Laudet, A. B. (2008). The impact of alcoholics anonymous on other substance abuserelated twelve-step programs. Recent Developments in Alcoholism, 18, 71-89.

Laudet, A. B., Morgen, K., \& White, W. L. (2006). The Role of Social Supports, Spirituality, Religiousness, Life Meaning and Affiliation with 12-Step Fellowships in Quality of Life Satisfaction Among Individuals in Recovery from Alcohol and Drug Problems. Alcohol Treat Q, 24(1-2), 33-73. doi:10.1300/Jo20v24no1_04.

Lazarus, R. S., \& Folkman, S. (1984). Stress, appraisal, and coping. New York: Springer.

Leighton, T., \& Barton, N. (2005). The origins, arrival and spread of residential Minnesota Model centres across the UK. In J. Strang \& M. Gossop (Eds.), Heroin Addiction and the British system-Treatment and Policy Responses (Vol. 2, pp. 175-186). London and New York: Routledge.

Mäkelä, K., Arminen, I., Bloomfield, K., Eisenbach-Stangl, I., Bergmark, K. H., Kurube, N., ... Zielinski, A. (1996). Alcoholics anonymous as a mutual-help movement: a study in eight societies. Madison, Wis.: The University of Wisconsin Press.

Malterud, K. (2012). Systematic text condensation: a strategy for qualitative analysis. Scand J Public Health, 4o(8), 795-805. doi:10.1177/1403494812465030.

Miller, W. R. (2003). Spirituality, treatment, and recovery. Recent Developments in Alcoholism, 16, 391-404.

Narcotics Anonymous. (2008). Basic Text (6th ed.). Chatsworth, CA: Narcotics Anonymous World Services.

Narcotics Anonymous. (2016). Information about NA. Van Nuys, CA: Narcotics Anonymous.

Ólafsdóttir, H. (2000). Alcoholics Anonymous in Iceland: from marginality to mainstream culture. Reykjavik: University of Iceland Press.

Olson, B. D., Jason, L. A., \& Hutcheson, T. D. (2005). Bridging professional and mutualhelp: An application of the transtheoretical model to the mutual-help organization. Applied and Preventive Psychology, 11(3), 167-178. doi:doi:10.1016/j.appsy.2005.06.001.

Olson, T., Tisdale, T. C., Davis, E. B., Park, E. A., Nam, J., Moriarty, G. L., ... Hays, L. W. (2016). God image narrative therapy: A mixed-methods investigation of a controlled group-based spiritual intervention. Spirituality in Clinical Practice, 3(2), 77-91.

Pargament, K. I. (1997). The Psychology of Religion and Coping. New York/London: Guilford Press.

Repstad, P. (2009). A softer God and a more positive anthropology: Changes in a religiously strict region in Norway. Religion, 39(2), 126-131. 
Schmidt, U. (2010). Norway-a religious pluralistic society? [Norge: et religiøst pluralistisk samfunn?] In P. K. Botvar \& U. Schmidt (Eds.), Religion in Norway today-Between secularization and sacralization [Religion i dagens Norge-Mellom sekularisering og sakralisering] (pp. 25-43). Oslo: Universitetsforlaget.

Smith, G. H. (1979). Atheism: the case against God. Buffalo, N.Y.: Prometheus Books.

Vederhus, J. K. (2017). Mind the gap—a European viewpoint on Alcoholics Anonymous. Addiction, 112(6), 937-938. doi:10.1111/add.136og.

Vederhus, J. K., Kristensen, O., Laudet, A., \& Clausen, T. (2009). Attitudes towards 12 -step groups and referral practices in a 12-step naive treatment culture; a survey of addiction professionals in Norway. BMC Health Services Research, 9, 147. doi:10.1186/1472-6963-9-147.

Vederhus, J. K., Laudet, A., Kristensen, O., \& Clausen, T. (2010). Obstacles to 12-step group participation as seen by addiction professionals: comparing Norway to the United States. Journal of Substance Abuse Treatment, 39(3), 210-217. doi:10.1016/j. jsat.2010.06.0o1.

Vederhus, J. K., Timko, C., Kristensen, O., \& Clausen, T. (2011). The courage to change: patient perceptions of 12-Step fellowships. BMC Health Services Research, 11, 339. doi:10.1186/1472-6963-11-339.

Vederhus, J. K., Timko, C., Kristensen, O., Hjemdahl, B., \& Clausen, T. (2014). Motivational intervention to enhance post-detoxification 12-Step group affiliation: a randomized controlled trial. Addiction, 109(5), 766-773. doi:10.1111/add.12471.

World Health Organization. (2010). Global Strategy to reduce the harmful use of alcohol. Geneva: World Health Organization.

Zahl, M. (2003). Spirituality and social work: a Norwegian reflection. Journal of Religion \& Spirituality in Social Work: Social Thought, 22(1), 77-90.

Zemore, S. E. (2008). An overview of spirituality in AA (and recovery). Recent Developments in Alcoholism, 18, 111-123. 